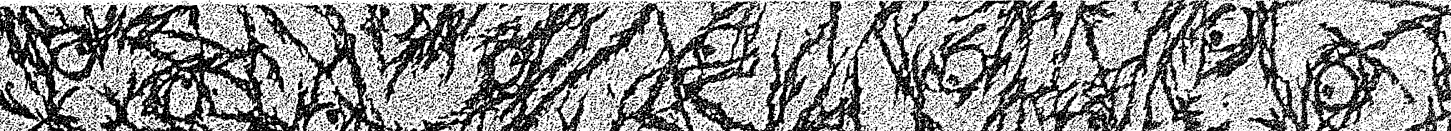

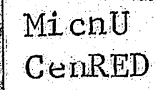

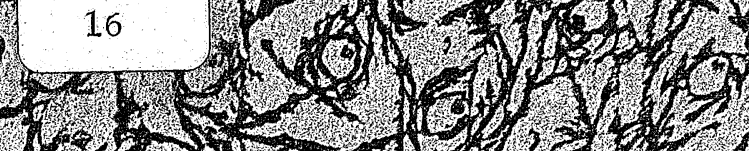

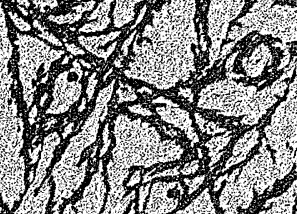

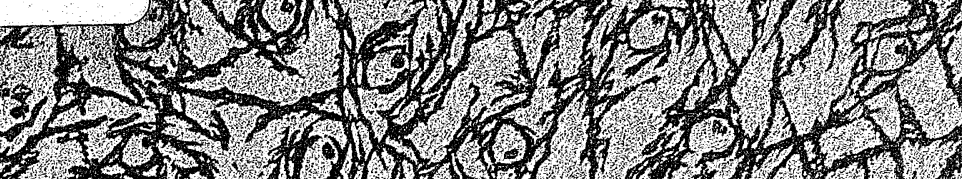

( t)

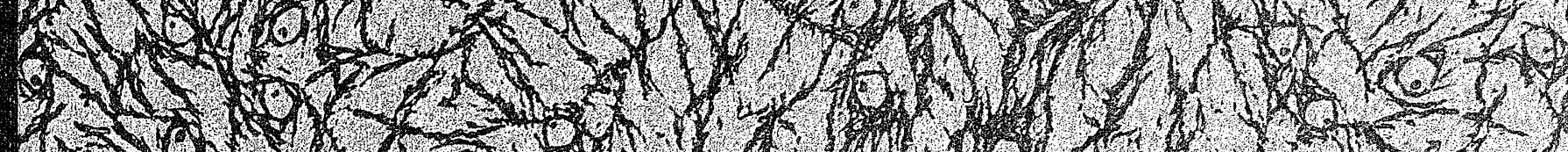

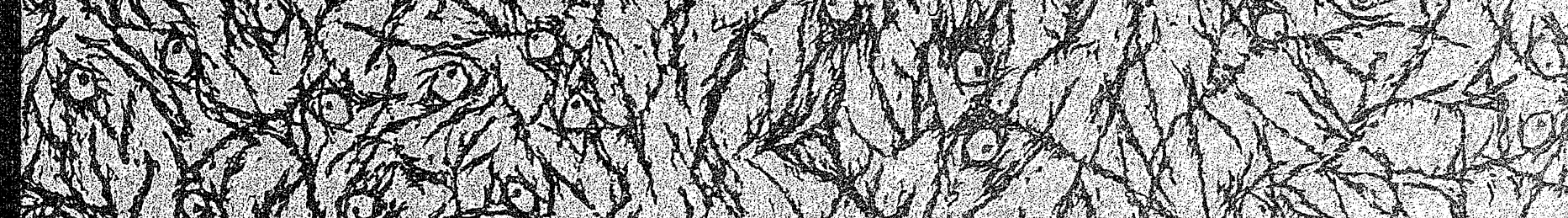

Dit 6.

2) 1 -

1.

a m 10

2 101,5

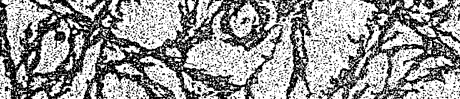

P.

(6) 121

(1)

$2(1,12021$

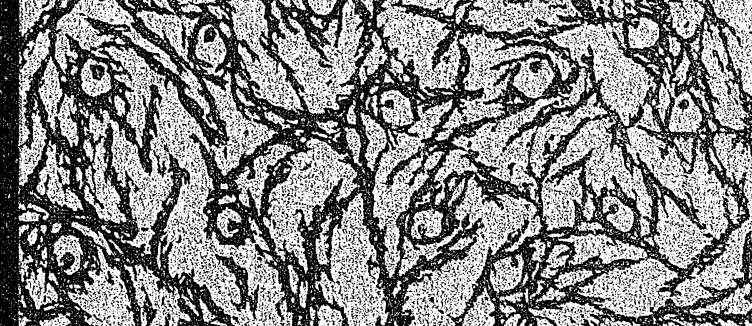

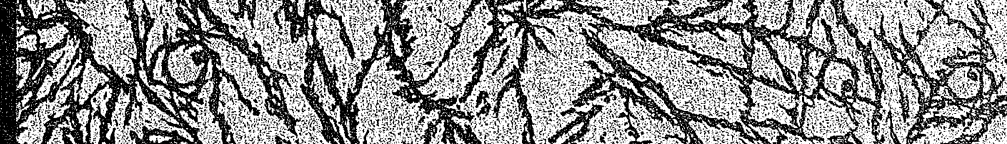

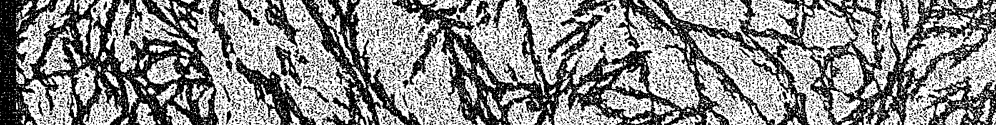

I 

CENTER FOR RESEARCH ON ECONOMIC DEVELOPMENT

THE UNIVERSITY OF MICHIGAN OCT 1871

Center for Research on Economic Development

University of Michigan

Ann Arbor, Michigan 48104 


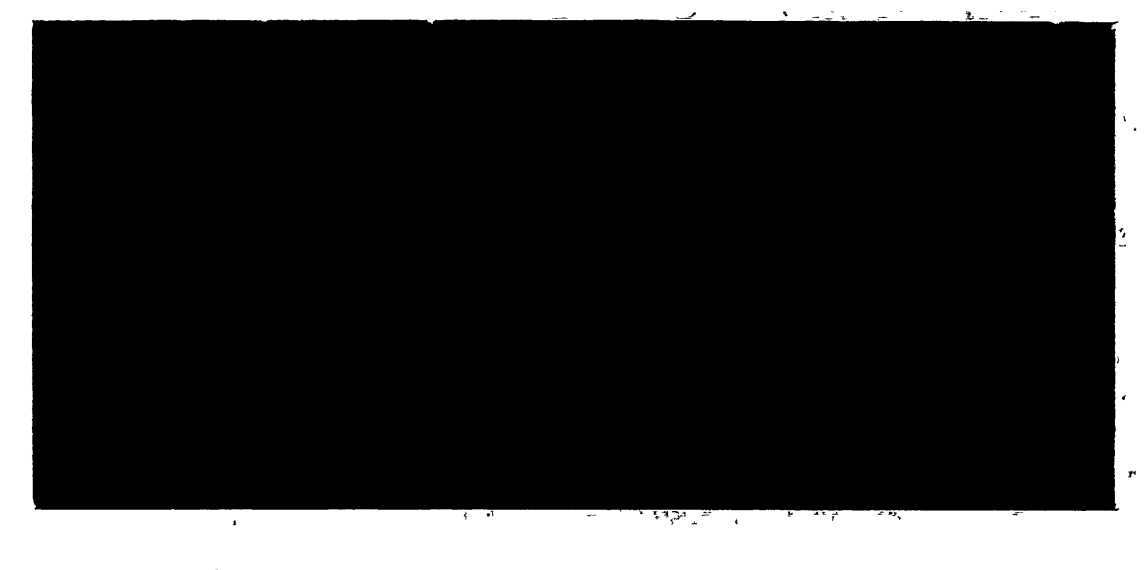




\section{The Use of Export Projections in Allocating Foreign Aid among and Domestic Resources within Developing Countries}

by

C. Michael Aho

Discussion Paper No. 16

July 1971
Center for Research on Economic Development University of Michigan
Ann Arbor, Michigan 48104



THE USE OF EXPORT PROJECTIONS IN ALLOCATING FOREIGN AID AMONG AND DOMESTIC RESOURCES WITHIN DEVELOPING COUNTRIES* C. Michael Aho University of Michigan

Foreign exchange shortages have been considered by many economists as the effective restraint to growth in the developing world. This is especially the case insofar as less developed countries (LDC's) are limited in their capacity to purchase imports from abroad that are needed to complement domestic factors of production. Exports obviously play an important role in this context since they constitute the primary source of foreign exchange for most LDC's. It is for this reason that a number of projections of future export earnings of LDC's have been made. These projections are presumably useful in decision making of various kinds. However, there is not much evidence that would indicate ways in which the projections have been or might conceivably be used. The purpose of this paper, accordingly, is to examine two such possible uses of export projections in connection with: (1) the allocation of foreign aid by donor countries among LDC's; and (2) the allocation of resources over time in individual LDC's.

Projecting international trade five and ten years or more into the future is certainly a difficult undertaking. 
Estimates must be made of the usual economic variables and parameters, including growth rates of income, production, prices, elasticities, and export-market shares. In addition, account must be taken of international agreements, institutional restraints, and the development of substitutes, to say nothing of such potential random effects as natural disasters or wars. After considering the problems inherent in making export projections, one is skeptical of the degree of accuracy that can be obtained and therefore how useful the projections can be as information for decision making. One way to determine this is to incorporate the information into analytical models of decision making.

Decision theory instructs us that information should be valued according to how it aids in achieving the objective at hand. ${ }^{1}$ This is found by comparing the results based upon the given information with what could have been achieved under perfect information. In other words, the greater the deviation from the optimal, the less valuable is the information. What this means is that we need a model to simulate the system in question, including an objective function that must be made explicit. Although the models to be presented are inevitably a simplification of reality, they demonstrate the potential loss involved in using imperfect information. As shown below, comparisons of different informational inputs will be facilitated by estimating losses in terms of a common objective function. 
Since our theoretical framework is based upon the "twogap" model of development, we begin in section I with a review of the basic assumptions of this model. In Section II, four sets of export projections of varying degrees of complexity are assessed in a model of the allocation of foreign assistance among selected IDC's. In section III, various export projections are evaluated in terms of a multisectoral planning model of the Pakistan economy. Some concluding remarks are given in section IV.

\section{The Two-Gap Model of Development}

The two-gap model focuses upon two supply-initiated constraints upon the ability of LDC's to sustain rapid rates of economic growth. These supply constraints have to do with the availability of savings (domestic capacity) and of foreign exchange (import capacity). While the two constraints are in reality not independent, the model is designed to emphasize the consequences of an LDC's inability to substitute between domestic and foreign sources of supply.

An augmented version of a two-gap model is set forth in equations (1)-(9) below. This model has been adapted from the works of Chenery and strout (1966), Fei and Ranis (1968), Maizels (1968), and Leamer and Stern (1970). There are eight variables: gross national product $(Y)$; consumption $(C)$; capital (K); gross investment (I); imports (M); exports (E); 
domestic savings (S); and the inflow of foreign assistance (F). Equations (1)-(4) are static accounting equations, three of which are independent. Equation (5) is a dynamic accounting equation indicating the change in the capital stock during an accounting period. Thus, there are four independent equations in eight unknowns, which require the additional specification of four behavioral equations $(6)-(9)$. Domestic savings are assumed in equation (6) to be a function of the change in $Y$. The potential savings in year $t$ are indicated by $\bar{S}_{t^{\prime}}$ and $s_{t}$ represents the realized savings. Imports are also a function in equation (7) of the change in $Y$, where $\bar{M}_{t}$ is the necessary imports in year $t$ and $M_{t}$ is realized imports. GNP is related to the capital stock in equation (8) in the simple Harrod-Domar relationship, with $\mathrm{k}$ as the gross capital-output ratio (COR) . Finally, exports are assumed to be exogenously determined in equation (9) and to grow at a rate of $x$ per cent per annum. The zero subscript represents the value of the variable in the base year. The model becomes operative when it is assumed that the system functions to achieve the maximum $Y$ attainable.

$$
\begin{aligned}
M+Y & =I+E+C \\
Y & =C+S \\
M & =E+F \\
I & =S+F \\
\frac{d K}{d t} & =I
\end{aligned}
$$




$$
\begin{aligned}
\frac{d \bar{S}}{d t} & =\frac{d Y}{d t} s \text { implying } S_{t} \leq \bar{S}_{t}=s_{0}+s\left(Y_{t}-Y_{0}\right) \\
\frac{d \bar{M}}{d t} & =\frac{d Y}{d t} m \text { implying } M_{t} \geq \bar{M}_{t}=M_{0}+m\left(Y_{t}-Y_{0}\right) \\
K & =k Y \\
E_{t} & \leq E_{0}(I+x)^{t} .
\end{aligned}
$$

The main parameters of this model are the COR $(k)$; the marginal propensity to save (s); the marginal propensity to import (m); and the rate of growth of exports $(\mathrm{x})$. The first three are subject to policy control and have been characterized by Chenery and Strout (1966) as "internal performance" parameters. 2 The fourth, $x$, is determined by exogenous factors, including the income elasticity of demand in advanced countries, their rates of growth, and various institutional factors.

The inequalities in equation (6), (7), and (9) represent the essence of the two-gap model, which requires adjustment of the gaps to the ex post equality indicated by equations (3) and (4).3 Foreign assistance (F) plays the dual role of supplementing savings and foreign exchange (export earnings) in order to establish the equality indicated by the accounting identities. The ex ante trade and savings gaps in year $t$ can be defined as follows:

$$
\begin{aligned}
& F_{t}^{T}=M_{0}+m\left(Y_{t}-Y_{0}\right)-E_{0}(1+x)^{t} \\
& F_{t}^{S}=k\left(Y_{t}-Y_{t-1}\right)-S_{0}-s\left(Y_{t}-Y_{0}\right) .
\end{aligned}
$$


Ex ante, there is no reason to believe $F^{S}=F^{T}$; therefore the effective constraint to growth will be $\operatorname{Max}\left[F^{S}, F^{T}\right]$. In other words, growth will proceed at the highest rate permitted by the most limiting factor, either insufficient foreign exchange or inadequate savings.

Assume that $\mathrm{F}$ will be forthcoming to fill the larger of these gaps. 4 In this case, the system is overdetermined since there are nine equations in eight unknowns. Overdetermination carries with it the notion of a disequilibrium analysis in which an adjustment process must occur in order to yield the accounting identities. One or more of the ex ante behavioral equations must no longer be effective, therefore justifying the inequalities in equation (6), (7), and (9). In trade-limited growth, a portion of the potential savings is frustrated. Under savings-limited growth, either actual imports will exceed required imports or potential exports will be frustrated, or both.

The two-gap model described thus far only considers savings and foreign exchange as restraints to growth without regard to other potential domestic bottlenecks, e.g., skilled labor, managerial talent, fixed land, etc. These constraints are usually combined under the title of absorptive capacity, which will be taken here in a broad sense to mean the lack of complementary domestic inputs. In the context of our model, this constraint is defined as ${ }^{5}$

$$
I_{t} \leq I_{0}\left(I+r^{*}\right)^{t},
$$


where $r^{*}$ is the maximum growth rate of investment and $I_{0}$ is investment in the base year.

The model as it now stands specifies three potential constraints to growth for an LDC, as noted in equations (3a), (4a), and (10). What the model says is that the maximum growth rate attainable for an LDC will be particularly dependent on the operative constraint and, also, the initial position of the economy. A closer look at the dynamic (comparative static) behavior of these gaps over a period of time will demonstrate the importance of accurate forecasts of economic magnitudes (particularly exports) for achieving developmental objectives. 6

A number of studies have concluded that LDC growth has been trade-limited. 7 Chenery and strout (1966), for example, have attributed this to the poor internal performance parameters in these countries, which they denoted as "historical performance," together with low growth rates for exports. In addition, the trade gap may well widen over time because the changes in the import requirements in a developing country are likely to exceed the changes in export revenues. This is assured if $\mathrm{m}$, the marginal propensity to import, is greater than $E_{0} / Y_{0}$, the initial average propensity to export. One of two conditions must be met in order to cause a reduction in the trade gap over time. ${ }^{8}$ Either

$$
m<M_{0} / Y_{0} \text { which implies } \frac{M_{t}}{Y_{t}}<\frac{M_{t-1}}{Y_{t-1}}
$$


or

$$
x>r=\frac{d Y / d t}{Y},
$$

that is, only if the initial average propensity to import is greater than the marginal propensity or the growth rate of exports exceeds the growth rate of $Y$. In light of the changing composition of demand and the traditional nature of most IDC exports, neither of these conditions is likely to be satisfied. Therefore, the trade gap will be "structural" unless export promotion can increase $\mathrm{x}$ sufficiently or import substitution can reduce $M / Y$ over time.

Under savings-limited growth the gap may also be increasing due to the compounding increases in investment as compared to the proportional increases in savings. One possible method of avoiding this situation is through the specification of a target rate of growth ( $\bar{x})$, which eventually will also become the country's growth rate of investment because of the Harrod-Domar relationship. Therefore, a sufficient condition for a declining savings gap is $s>k \bar{r}$, which could be obtained by means of some type of domestic austerity. ${ }^{9}$ However, despite the austerity measures, the "demand" for foreign assistance may not decrease because the foreign exchange constraint might become operative for the reasons cited earlier. Because of the lack of substitution between domestic and foreign resources, the LDC's dependence upon inflows of $F$ increases. 
It can be seen from our discussion that attempts must be made, ex ante, to reduce the gaps if the objective of the LDC is to achieve self-sustaining growth. Two points are of importance here. First, the difficulty involved in expanding exports and the potential instability of export earnings over time may make dependence upon export promotion appear relatively undesirable as an alternative. Second, the asymmetry of the model must be recognized, i.e., the fact that the constraints are not independent. 10 Changes in export earnings have an impact upon the level of savings, but not vice versa. Viewed alternatively, imports can supply final goods directly, whereas domestic production is dependent upon complementary imports. These two phenomena manifest themselves in the structural disequilibrium that characterizes the economic situation in many LDC's. This rigidity in the productive structure is also sustained by the use of overvalued exchange rates in making investment decisions. Foreign exchange is not valued at the level of its productivity on the margin, thereby causing an underestimation of the potential returns from investing in a trade-related activity.

It is imperative, therefore, that the excess consumption or imports resulting from gap adjustments be converted into import substitution and/or export expansion. In the case of import substitution an alternative source of supply is created, thus facilitating the mobility of resources. 
Secondary effects of the substitution, however, will cause changes in the other macroeconomic variables and parameters that must be taken into account. When evaluating the impact of a change in the composition of demand, it is necessary to consider the "total" impact, both direct and indirect. In section III below, a comprehensive model will be developed that will provide a scheme for ranking the various trade activities along with providing scarcity prices for the primary factors of production (e.g., foreign exchange).

The model described in this section is subject to many obvious criticisms, in particular, its highly aggregative design. It may nevertheless provide some insight into the workings of a developing economy, and, as such, it will be used in the following sections as a foundation for the evaluations of export projections on a macroeconomic level and for analyzing the structural relations in a disaggregated programming model of the Pakistan economy. 11 Additional implications and limitations of the model will be discussed as they arise in the course of the paper.

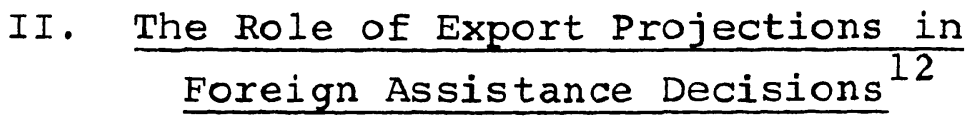

In the preceding section, foreign assistance (F) was shown to play a dual role in the growth process of LDC's as a source of external capital and a foreign exchange 
supplement. It was assumed that the inflow of assistance would be sufficient to fill the larger of the two gaps, i.e., the dominant constraint. In reality, however, the supply of $\mathrm{F}$ is limited and it should be treated as a scarce resource. The allocation of $F$ must therefore be based upon the most accurate information available. Export projections, in conjunction with forecasts of import requirements, could provide an estimate of the foreign exchange gap. Since the trade gap can be considered to be the effective constraint to growth in many LDC's, those with control over the disbursement of $F$ would benefit from accurate projections insofar as this would sharpen their basis for judgment and assist them in the implementation of their objectives.

Because exports constitute the major source of foreign exchange for most LDC's, they shall be the primary object of our attention in our model of foreign assistance decisions. Four projections will be evaluated as reported in or otherwise derived from Balassa (1964), Maizels (1968), Chenery and strout (1966), and a set of naive projections constructed to establish a reference point for relative comparisons. The first three projections varied as to the methodology involved, particularly the manner in which the trade flows and exporting countries were disaggregated.

Balassa's projections were based upon exports of 50 commodities from each of 4 less developed regions (Latin America, Africa, Middle East, and Asia) to each of 4 
industrialized regions (North America, Western Europe, Japan, and Australia-New Zealand-South Africa). ${ }^{13}$ The projections were for 1970 and 1975 under two income assumptions for the industrialized regions. Maizels used a combination approach broken down by commodities and countries with reference especially to the Overseas Sterling Area. He provided estimates of the rate of export growth from all LDC's to the industrialized world for about one-half of the commodities used in the Balassa study. Since Maizels did not cover as many commodities, it was necessary to use the Balassa estimates in those places where Maizels made no projection. The projection referred to below as "Maizels" is, therefore, a composite of both projections. It was felt, however, that the differences between the two projections were substantial enough for evaluation purposes. The third set of projections was derived from the work of Chenery and Strout, who implicitly projected the rate of export growth for 50 IDC's using a simple aggregate model. The emphasis of their work was in estimating the foreign resource requirements of the developing world over time, i.e., the magnitude of the foreign exchange or savings-investment gaps. Being less disaggregated, it was thought that their projections might provide a useful contrast to the others mentioned. Finally, a set of naive projections was made for reference purposes for the period $1960-67$ by simply extrapolating the growth rate of exports from the previous 
seven-year period. 14 If export growth in that period exceeded 6 per cent per annum, then the absolute increment for that period was used.

It is a matter of common observation that foreign assistance decisions reflect a myriad of objectives on the part of donor countries and international agencies that cannot be captured in a relatively simple model. It seems interesting and potentially important nevertheless to examine how aid allocations might be made on the basis of given empiriaal information, obtained in this instance from export projections, with certain specified objective functions for the decision makers.

We thus assumed for purposes of analysis that a single international agency or consortium of donor countries had responsibility for allocating a fixed amount of funds among 12 selected LDC's. ${ }^{15}$ The countries are listed in Table 1 together with the percentage errors for each of the four projections. That is, in each column, there is indicated in percentage terms the variation between projected exports for 1970 and actual exports based on 1967 data, which were the most recent available at the time of writing. ${ }^{16} \mathrm{~A}$ positive sign indicates that the projection exceeded the actual, and conversely for a negative sign. The mean errors for each projection are shown in the last three lines of Table 1.17 These permit some overall comparisons to be made among the individual projections. 
Table 1

Percentage and Mean Errors Between Projected and Actual Exports for 1967 for Selected LDC's

\begin{tabular}{|c|c|c|c|c|c|}
\hline Country & $\begin{array}{l}\text { Actual Exports } \\
\text { (Based upon } 1967 \\
\text { Data) (Mill. \$) }\end{array}$ & Balassa & Maizels & Naive & $\begin{array}{l}\text { Chenery } \\
\& \text { Strout }\end{array}$ \\
\hline Algeria & $\$ 724$ & $-30 \%$ & $-30 \%$ & $-25 \%$ & $-30 \%$ \\
\hline Ghana & 265 & 29 & 27 & 16 & 26 \\
\hline Morocco & 424 & 17 & 18 & 34 & 0 \\
\hline Nigeria & 667 & -7 & -2 & -5 & 9 \\
\hline Sudan & 213 & -1 & 14 & 35 & 40 \\
\hline Tanzania & 217 & -1 & 1 & 22 & -4 \\
\hline Mexico & 1145 & -12 & -7 & -9 & 7 \\
\hline Colombia & 510 & 5 & 10 & -13 & 16 \\
\hline Israel & 554 & -44 & -41 & -39 & 1 \\
\hline Egypt & 559 & -3 & 7 & 22 & 11 \\
\hline South Korea & 320 & -52 & -44 & -44 & -28 \\
\hline Ceylon & 338 & 15 & 27 & 50 & 30 \\
\hline \multicolumn{6}{|l|}{ Mean Errors } \\
\hline $\begin{array}{l}\text { Mean Absolut } \\
\text { Error }\end{array}$ & & .180 & .190 & .260 & .168 \\
\hline $\begin{array}{l}\text { Mean Square } \\
\text { Error }\end{array}$ & & .0594 & .0418 & .0872 & .0346 \\
\hline $\begin{array}{l}\text { Square Root } \\
\text { of MSE }\end{array}$ & & .244 & .204 & .295 & .186 \\
\hline
\end{tabular}

Note: A positive error indicates that the projection was higher than the actual value, and conversely for a negative error. 
It was further assumed that the decision was made to allocate the limited funds over a five-year period, with 1962 taken as the base year. 18 A five-year period was chosen on the grounds that this was long enough for the aid to be used effectively, yet short enough that no significant changes in the composition of demand would occur that might render the constant parameter assumption implausible.

The decision model used for analysis was a simple fiveyear, comparative static model of economic growth. The rationale for the model is that it would provide the decision maker with a possible means of systematically allocating the limited funds and making comparisons among the LDC's on a common basis. The structure of the model is essentially the same as the two-gap model described earlier. There are 49 constraints, 4 for each of the 12 LDC's and the limit on available F. The constraints are repeated here for the sake of reference: ${ }^{19}$

$$
\begin{aligned}
& F_{i} \geq \frac{k_{i}\left(Y_{i}-Y O_{i}\right)}{5}-S O_{i}-s_{i}\left(Y_{i}-Y O_{i}\right) \\
& F_{i} \geq M_{i}+m_{i}\left(Y_{i}-Y O_{i}\right)-E_{i} \\
& k_{i}\left(Y_{i}-Y O_{i}\right) \leq \sum_{t=1}^{5}\left(1+r_{i}^{*} t^{t} O_{i}\right. \\
& Y_{i} \geq Y O_{i} \text { for } i=1, \ldots, 12
\end{aligned}
$$

where IO, SO, MO, YO, are the base-year (1962) values of investment, savings, imports, and GNP, respectively. F, Y, I, and $E$ are the 1967 values of the respective variables. The 
subscripts denote the various countries. The last constraint (14) is a policy constraint, which requires that aid be disbursed so that each LDC would maintain at least a zero rate of growth over the period.

The selection of criteria for disbursement is difficult because, as already noted, donors share such a complex mixture of objectives, many of which cannot be expressed in quantitative form. For reasons of mathematical tractability, it was necessary to abstract from political objectives and use an approach in which $F$ was allocated acoording to its marginal productivity. The selection of an objective function was not straightforward, however. Certainly the value of $F$ should depend upon the extent to which it facilitates a greater use of domestic resources, but an element of choice exists because of differences in country size, initial position of the economy, and the effective constraint. 20 Donors are generally concerned with the LDC performance in utilizing the aid, but the interdependence of the internal parameters makes the measurement of performance complicated. ${ }^{21}$ The problem of choosing an objective function actually narrows down to the controversy over the determinants of economic growth. Should $F$ be allocated to those who are most likely to sustain high levels of performance or, alternatively, concentrated in those LDC's where it might improve performance according, say, to some hypothesis such as the "big push?" In order to cope with some of these difficulties, 
three alternative objective functions were specified, as follows :

$\begin{array}{ll}\text { (OF1) } & \text { Maximize } \sum_{i=1}^{12} \mathrm{Y}_{i} / \mathrm{YO}_{i} \\ \text { (OF2) } & \text { Maximize } \sum_{i=1}^{12}\left(\mathrm{Y}_{i}-\mathrm{YO}_{i}\right) \\ \text { (OF3) } & \text { Minimize } \sum_{i=1}^{12} \mathrm{~F}_{i} \text { subject to } \mathrm{Y}_{i}=1.2 \mathrm{YO}_{i} i=1, \ldots, 12\end{array}$

The first objective function is equivalent to maximizing the average percentage increase in GNP of the 12 selected LDC's over the period. The implications of using this function can be illustrated by examining the marginal productivity of $F$ for each constraint:

for (11)

$$
\frac{\Delta\left(Y_{i} / Y_{i}\right)}{\Delta F}=\frac{1}{\left(\frac{k_{i}}{5}-s_{i}\right) Y O_{i}}
$$

for (12)

$$
\frac{\Delta\left(Y_{i} / Y_{i}\right)}{\Delta F}=\frac{1}{m_{i} Y_{i}}
$$

for (13)

$$
\frac{\Delta\left(Y_{i} / Y_{i}\right)}{\Delta F}=0
$$

Although the productivities are dependent upon the internal parameters, the more important factor is the inverse relationship with country size. Smaller LDC's would be favored in aid disbursal under this criterion. To the extent that smaller LDC's suffer from underutilization of resources and/ or poor internal performance, concentration of assistance in these countries might follow the "big push" phenomena. 
The second maximand is framed in terms of increments of GNP. Equivalently, it could be considered as a maximization of growth of the developing world as a whole. 22 The productivities of aid in achieving this objective are similar to those under the first objective, only without the reciprocal of initial GNP as weights. Thus the disbursal is determined solely on the basis of past performance as reflected in the parameters.

The third objective function is different from the other two because the objective variable is the total amount of aid disbursed, subject to a side constraint on terminal year GNP. In this case, aid is to be allocated in an attempt to allow each LDC to obtain a 20 per cent increase in GNP over the period (approximately 3.9 per cent per annum). This reflects the goal that some donors might want to bring all IDC's up to a certain standard of development. This objective function also provides a contrast with the first two maximands because it can be considered an "anti-self help" criterion. (OF1) and (OF2) encourage improvement on the part of the individual LDC's, while this criterion does not. The model, together with one of the three objective functions, can now be used to evaluate the four sets of export projections noted. First, the optimal allocation of $F$, in light of perfect foresight, was calculated using actual 1967 export data. This establishes the extremal value of the objective function which will be compared to the results 
obtained using the projections. It is designated as "optimal" in Tables 2-4 that summarize the results. The second step in the procedure was to determine the optimal aid distribution based on the projections. This aid was then used in conjunction with the actual exports to find the effect upon the assumed objective. 23 The discrepancy between the extremal function values will then provide an indication of the "loss" associated with using the particular export projections as information for decision making in this context. 24

As an illustration consider the case where the trade gap is effective. In equation form:

$$
\begin{aligned}
& M(Y)-E_{A}=F^{*}, \text { which Yields } Y^{*} \\
& M(Y)-E_{P}=F_{P^{\prime}} \text { then } M(Y)-E_{a} \neq F_{P^{\prime}} \text { yielding } Y
\end{aligned}
$$

where $M(Y)$ is the import function based upon national income, and $E_{A}$ and $E_{P}$ are actual and projected exports respectively. In (15) the optimal allocation of aid, $\mathrm{F}^{*}$, leads to the optimal value of national income, $\mathrm{Y}^{*}$. In (16) the allocation of funds based upon the projections, $F_{P^{\prime}}$ does not equal the gap between imports and actual exports and a different value of $\mathrm{Y}$ emerges. In the linear programming problem associated with (16), the constraints assuring a zero rate of growth (14) were removed. Negative growth rates could therefore result if the $F$ allocated was not sufficient to fill the base year gap and/or exports were less than those in the base year. 
Since, in reality, donors may be interested in the well being of the individual countries, we thought it desirable to establish a more comprehensive criterion for evaluation that would measure the variation of the individual country growth rates about the optimal. Ideally, we would prefer to use an objective function that would maximize some function of the growth rates while minimizing the variation in individual country growth. However, the linear form of the model makes it impossible to incorporate both simultaneously. For this reason, a second criterion for evaluation was established, the squared-error loss (SEL), 25 i.e., the squared difference between the growth rates achieved under the optimal and the projected for each country. This criterion captures the individual discrepancies which tend to cancel out in the aggregate.

Let us now examine the results for each of the objective functions. The results of the evaluation for the first objective function, which was to maximize the percentage increase in GNP of the countries over the period, are given in Table 2. The columns list the proportion of aid given to the LDC's and the resulting percentage change in income for each of the four export projections and for the optimal using the actually observed export data. The average percentage increase is the value of the objective function. The difference between the optimal (125.2) and those obtained based on the projections is substantial. All of the 
projections yielded results in the same range. The Balassa and Chenery and Strout results were almost identical, although both were 8 per cent below the optimal. Thus, even in the aggregate the export projections did not fare well in achieving the stated objective. From a decision maker's point of view, this of course casts doubt upon their usefulness as information. Using the SEL criterion, Maizels' estimates were slightly better than Balassa's, while the naive extrapolations were considerably poorer.

The results using the second objective function are listed in Table 3. Here the value of the maximand is the percentage increase in income for the countries as a whole. The values for each of the projections again fall in a small range, with no projection appearing clearly superior. The discrepancy between the optimal and the projections is smaller, primarily because the maximand is independent of country size. Increments of GNP are treated equally regardless of origin, therefore giving the aggregate an upward bias. A comparison of the SEL's yields quite interesting results. First notice that the values of the SEL's are considerably higher than those obtained using the first objective function. This indicates a wider spread of the individual growth rates about the optimal. Recall that the use of this objective function implies a disbursement of aid to those countries with good performance parameters. Thus, the individual growth rates are highly sensitive to a misspecification of export earnings, causing a wide variation in the 
Table 2

Results Using Objective Function One: Maximize the Percentage Increase in GNP of the Individual Countries over the Period

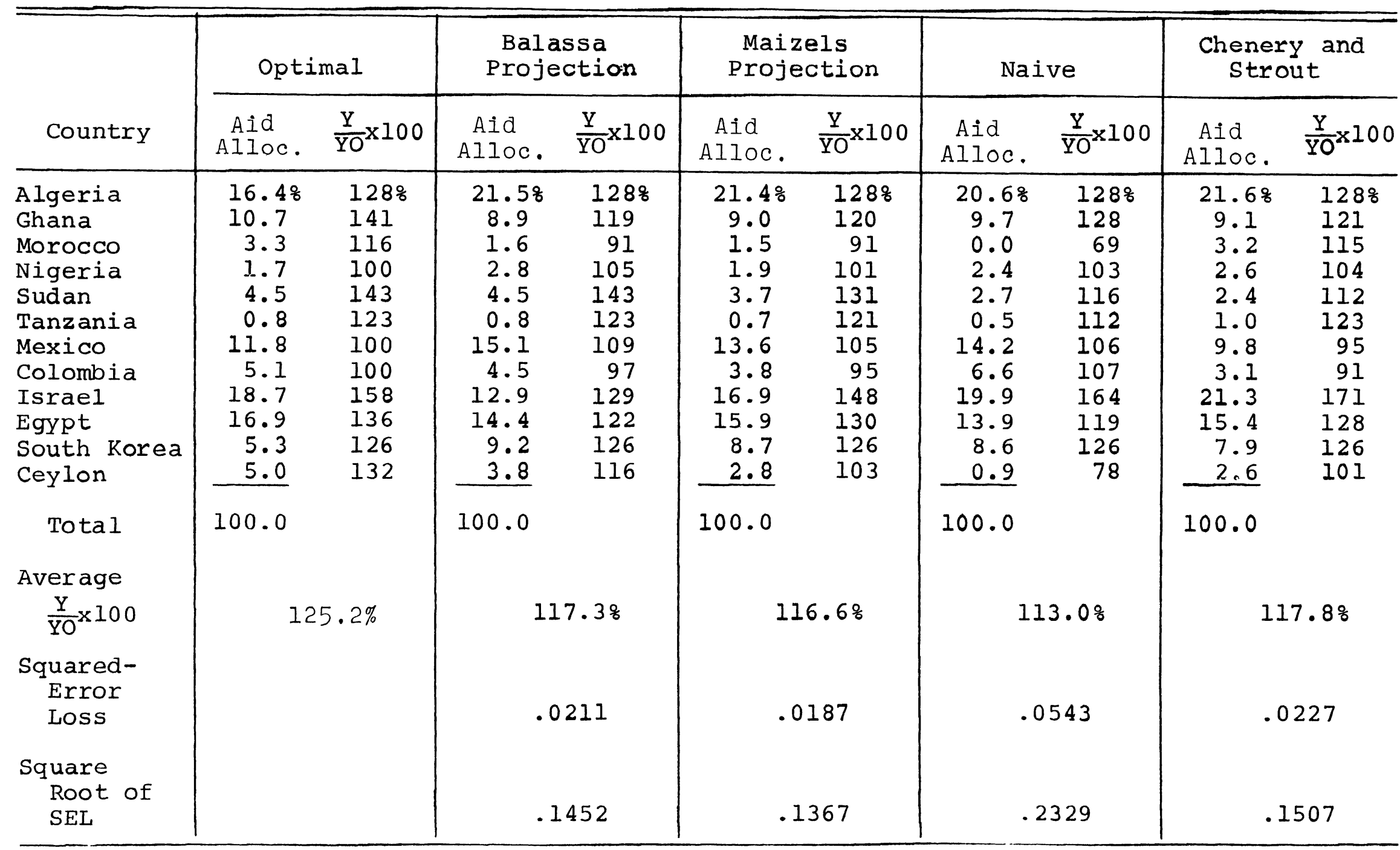


Table 3

Results Using Objective Function Two: Maximize the Percentage Increase in GNP for the Countries as a Group

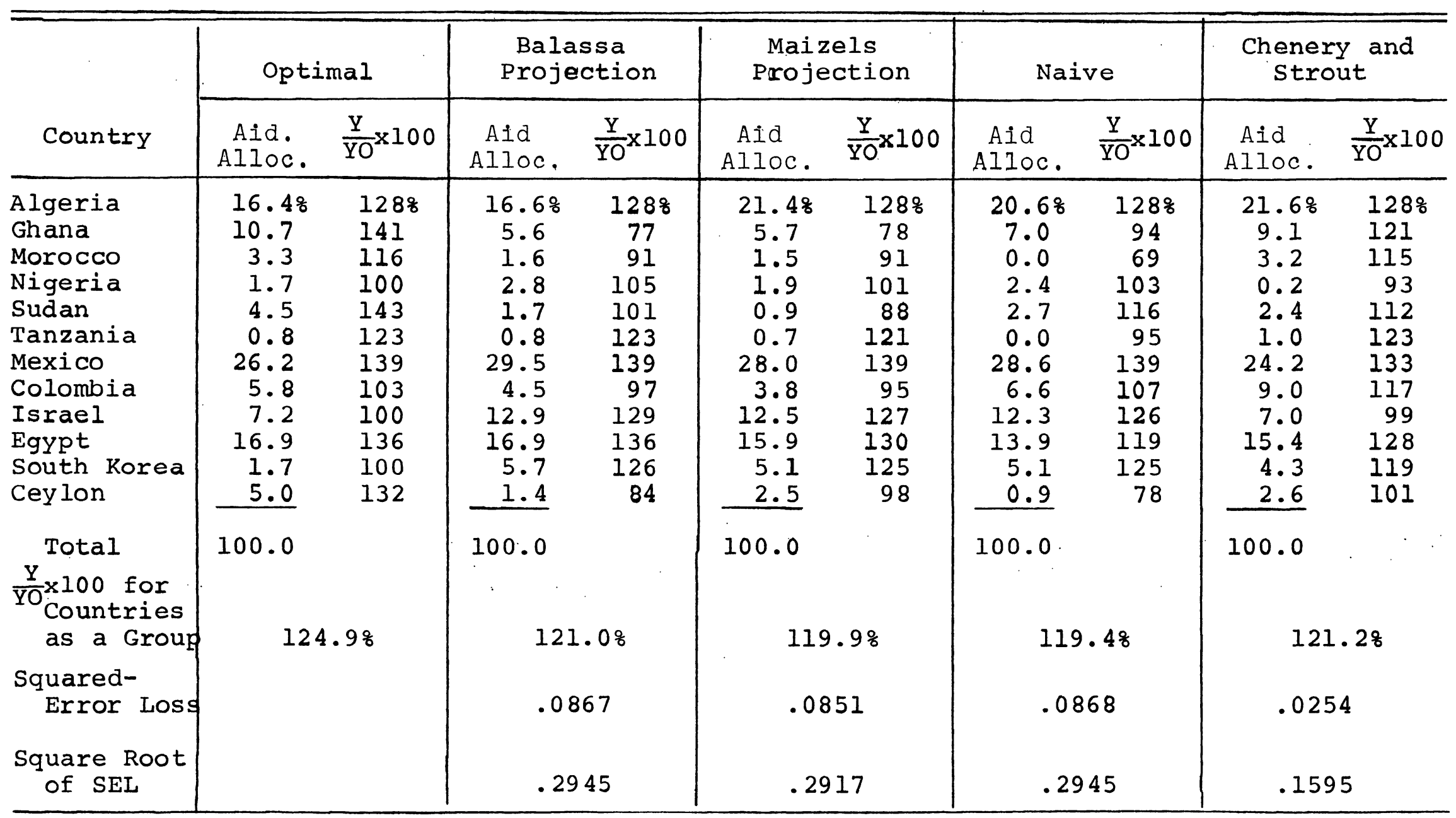


Table 4

Results Using Objective Function 3: Minimize the Amount of Foreign Assistance Necessary to Increase Each Country's GNP by 20 Per Cent Over the Period

\begin{tabular}{|c|c|c|c|c|c|c|c|c|c|c|}
\hline \multirow[b]{2}{*}{ Country } & \multicolumn{2}{|c|}{ Optimal } & \multicolumn{2}{|c|}{$\begin{array}{l}\text { Balassa } \\
\text { Projection }\end{array}$} & \multicolumn{2}{|c|}{$\begin{array}{l}\text { Maizels } \\
\text { Projection }\end{array}$} & \multicolumn{2}{|c|}{ Naive } & \multicolumn{2}{|c|}{$\begin{array}{l}\text { Chenery and } \\
\text { Strout }\end{array}$} \\
\hline & $\begin{array}{c}\text { Aid. } \\
\text { Alloc. }\end{array}$ & $\frac{Y}{Y O} \times 100$ & $\begin{array}{l}\text { Aid } \\
\text { Alloc. }\end{array}$ & $\frac{Y}{Y O} \times 100$ & $\begin{array}{l}\text { Aid } \\
\text { Alloc. }\end{array}$ & $\frac{Y}{Y O} \times 100$ & $\begin{array}{l}\text { Aid } \\
\text { Alloc. }\end{array}$ & $\frac{Y}{Y O} \times 100$ & $\begin{array}{l}\text { Aid } \\
\text { Alloc. }\end{array}$ & $\frac{Y}{Y O} \times 100$ \\
\hline $\begin{array}{l}\text { Algeria } \\
\text { Ghana } \\
\text { Morocco } \\
\text { Nigeria } \\
\text { Sudan } \\
\text { Tanzania } \\
\text { Mexico } \\
\text { Colombia } \\
\text { Israel } \\
\text { Egypt } \\
\text { South Korea } \\
\text { Ceylon }\end{array}$ & $\begin{array}{r}15.0 \% \\
9.0 \\
3.3 \\
6.3 \\
3.0 \\
0.7 \\
19.2 \\
9.7 \\
11.2 \\
14.1 \\
4.4 \\
4.1 \\
\end{array}$ & $\begin{array}{l}1200^{\circ} \\
120 \\
116^{a} \\
120 \\
120 \\
120 \\
120 \\
120 \\
120 \\
120 \\
120 \\
120\end{array}$ & $\begin{array}{r}17.68 \\
6.3 \\
1.4 \\
6.5 \\
2.6 \\
0.7 \\
19.7 \\
8.0 \\
14.8 \\
12.6 \\
7.3 \\
2.5 \\
\end{array}$ & $\begin{array}{l}1288 \\
97 \\
91 \\
125 \\
121 \\
123 \\
129 \\
117 \\
149 \\
122 \\
126 \\
104\end{array}$ & $\begin{array}{r}18.8 \% \\
6.8 \\
1.4 \\
6.1 \\
2.1 \\
0.6 \\
19.6 \\
7.9 \\
15.4 \\
12.2 \\
7.3 \\
1.8 \\
\end{array}$ & $\begin{array}{c}1288 \\
98 \\
91 \\
121 \\
108 \\
118 \\
125 \\
115 \\
147 \\
114 \\
126 \\
91\end{array}$ & $\begin{array}{c}18.38 \\
7.6 \\
1.2 \\
6.7 \\
1.1 \\
0.3 \\
20.6 \\
10.7 \\
15.5 \\
10.6 \\
7.4 \\
0.0 \\
\end{array}$ & $\begin{array}{l}1288 \\
106 \\
87 \\
123 \\
92 \\
105 \\
127 \\
127 \\
146 \\
103 \\
126 \\
66\end{array}$ & $\begin{array}{c}21.48 \\
7.8 \\
3.4 \\
5.0 \\
1.0 \\
0.9 \\
18.2 \\
8.1 \\
11.6 \\
13.3 \\
7.4 \\
1.8 \\
\end{array}$ & $\begin{array}{l}1288 \\
100 \\
115 \\
113 \\
89 \\
123 \\
115 \\
111 \\
119 \\
112 \\
126 \\
89\end{array}$ \\
\hline Total & 100.0 & & 100.0 & & 100.0 & & 100.0 & & 100.0 & \\
\hline $\begin{array}{l}\text { Average } \\
\qquad \frac{Y}{Y} \times 100 \\
\text { Foreign Aid } \\
\text { Disbursed } \\
\text { (in mill- } \\
\text { ions) }\end{array}$ & \multicolumn{2}{|c|}{$119.7 \%$} & 11 & .38 & 115 & $.2 \%$ & 111 & .48 & 11 & $.6 \%$ \\
\hline $\begin{array}{l}\text { Squared- } \\
\text { Error Loss } \\
\text { Square Root } \\
\text { of SEL }\end{array}$ & & & .0 & 03 & .02 & 48 & .22 & 33 & .0 & 98 \\
\hline
\end{tabular}

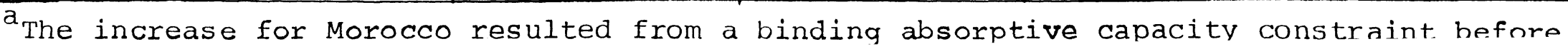


results. If the goal of the decision makers were to distribute aid to those LDC's where performance was likely to be greatest, then, with the exception of the Chenery and Strout estimates, the projections certainly leave something to be desired. It is noteworthy that the naive projection in Table 3 performed just as well as Balassa's, using both criteria for evaluation.

The third set of results differs somewhat from the previous two because the amount of $F$ to be disbursed was allowed to vary. In this instance, the model was used to determine the amount of foreign assistance necessary to allow each LDC to achieve an increase of 20 per cent in GNP over the period. This complicates the results by interjecting another variable into the system, which is considered as an objective variable. The complication is not too severe, however, since only two cases arise:

1) If optimal $F$ is greater than projected $F$, then resulting growth rates will suffer both from poor estimation and an insufficiency of funds.

2) If optimal $F$ is less than projected $F$, the growth rate of each LDC might be closer to the optimal, but perhaps not close enough to justify the extra F which was allocated.

It can be seen from the results in Table 4 that the Balassa projection, in the aggregate, is almost as successful in achieving the objective under perfect information. 
However, the loss in this case is reflected in the total aid disbursed since the amount corresponding to Balassa's projection is $\$ 600$ million greater than in the case of perfect information. According to the SEL criterion, Chenery and Strout fared almost as well as Balassa while disbursing $\$ 800$ million less, although here the Balassa results generally exceeded the optimal while the Chenery and strout results were generally below the optimal.

Looking at the specific results of two individual countries will give an indication of the implications of grossly misspecified export earnings. An illustration of the consequences of an overestimate is given by Ghana where the large fall in that country's share of cocoa trade caused all of the projections to be high. Under (OFl) the discrepancy between the optimal and Balassa was 141 as compared to 119 , while under (OF2) the discrepancy was 141 as compared to 77 . In the latter case the poor estimates in "higher priority" LDC's together with the overestimate of Ghana's exports caused her growth rate to be cut severely. The consequences of an underestimate of export revenues are demonstrated by Algeria where the failure to anticipate increases in petroleum exports caused all of the projections to be low. Notice that the percentage increase is the same (128) for all of the projections, under both (OF1) and (OF2), despite different amounts of aid. This indicates that the economy was at its absorptive constraint, where the productivity of aid is zero, thus allowing the excess $F$ to be of no use. 26 
Looking at the results overall for the three objective functions, no single projection stands out as superior to the others. It can be concluded, moreover, that none of the projections yielded results that were good enough to have justified their use as an input to decisions. In many instances, the projections influenced allocations of aid that had an adverse effect upon the level of income in the IDC's and caused a wide variation in the growth rates achieved by the individual countries. The relative comparisons between the projections show that, in general, the naive extrapolations fared worse than the more detailed studies, although in some cases, e.g., under (OF2), the naive extrapolations did perform remarkably well relative to the others. The most consistent of the projections were those of Chenery and strout. Two factors may have played a part here. First, their projections were based upon two additional years of data, which is consistent with the a priori view that projections are more accurate the closer is the terminal year for which the projections are made. Second, and more importantly, they used a country approach to disaggregate the trade flows. This enabled them to use a less detailed projection procedure. Although it could be claimed that the other broad regional projections were not disaggregated properly for use here, this is hard to substantiate. It would thus appear that the Balassa-Maizels type of projections may not be very useful in the context of aid allocation to selected LDC's. 
Although the procedure used in the foregoing evaluations might be dependent upon the 12 LDC's which were chosen, it could be expanded to include any number of countries. The evaluations conducted here were intended to illustrate the effects of using export projections as information when planning the disbursal of aid among LDC's. An expanded and more detailed version of this procedure could be used to conduct a thorough study of the art of projecting exports themselves. However, the problem would still remain that the underlying causal influences are assumed unchanged. This drawback can perhaps be avoided somewhat by using a more detailed multisectoral model to which we will now turn.

III. The Role of Export Projections in the Formulation of Development Plans Within IDC's

Earlier we saw the need for individual LDC's to attempt, ex ante, to reduce their foreign exchange gap over time. A well-coordinated development plan, therefore, should allocate resources for import substitution and/or export promotion. Export projections, if accurate, could play an integral role in this aspect of development planning. However, if resources were misdirected due to inaccurate information, this could cause development objectives to suffer. Poor information would provide a biased view of the availability of foreign exchange, and also might divert resources from their most productive uses. 
In this section, an attempt is made to evaluate the role of export projections in the formulation of a development plan. A multisectoral model is used for this purpose in order to obtain a broad, overall view of the development process. Unlike the simple two-gap analysis which assumes only aggregate effective restraints to development, a multisectoral model allows for interdependence among the sectors, as well as varying capital and import requirements. These aspects of the model can be incorporated into a linear programming framework in which the constraints are in terms of sectoral requirements. This permits us to observe the "total" impact, including secondary effects, of a change in some key variables, in the present case a misspecification of future exports.

The linear programming formulation of the development process has the further advantage of enabling us to estimate the optimal allocation of resources in our open and growing economy in which simultaneous decisions must be made on investment, consumption, and the future levels and composition of foreign trade. Solutions to the model used below make an explicit choice between domestic production and imports. The criterion used to determine the optimal pattern of trade and investment is the opportunity cost of resources on the margin. Chenery (1961) called this the doctrine of "comparative cost." 27 The opportunity costs are the "shadow prices" obtained from the dual linear programming problem, which is 
consistent with the optimal allocation of resources in the primal. These "shadow prices" provide the link between classical comparative advantage and growth theory.

Solution of the programming problem also implicitly gives estimates of the aggregate parameters used in the twogap model. 28 Since the composition of demand can change in response to resource availabilities, the comprehensive nature of the model will allow us to observe changes in these parameters. Thus, we may be able to evaluate the export projections in terms of their effect on the overall "performance" of the economy, as reflected in the parameters. Pakistan was the country chosen for use in the evaluations, due primarily to the availability of the regional 35-sector model of that economy constructed by MacEwan (1971). The base year for MacEwan's work was 1964-65, which coincided with the base year of Pakistan's Third Five-Year Plan. The model is a comparative static, open Leontief model with inequality constraints. Each of the model's variables was incremental over the planning period, here assumed to run from $1964-65$ to $1969-70.29$

MacEwan's model is especially noteworthy for its wealth of data and the incorporation of new features into this variety of linear programming problems. That is, besides a regional division between East and West Pakistan, the model distinguishes between competitive and noncompetitive imports and allows for substitution between foreign and domestic sources of supply. Other distinctive features of the model 
will be apparent when the evaluations are discussed below. The full model is presented in the appendix to this paper. Here only the general concepts of it will be discussed as a prelude to the evaluations of the export projections. The objective (welfare) function of the model is to maximize incremental per capita consumption over the period. That is:

$$
\operatorname{Maximize} \frac{\mathrm{C}^{e}}{\mathrm{~N}^{e}}+\frac{\mathrm{C}^{\mathrm{W}}}{\mathrm{N}^{\mathrm{W}}}
$$

where $C^{e}$ and $C^{W}$ are aggregate consumption in East and West Pakistan, respectively, 30 and $\mathrm{N}^{\mathrm{e}}$ and $\mathrm{N}^{\mathrm{W}}$ are their respective estimated populations in 1970. This function is intended to reflect the goal of raising per capita living standards within an LDC. Although the function is unidimensional, other policy objectives can be incorporated into the model in the form of constraints. Solution of the model will then simultaneously satisfy these explicit goals while maximizing the change in per capita consumption. One of these objectives which should be noted is that investment in the terminal year will be sufficient to sustain growth in the future. Thus, the function actually maximizes the level of the consumption path in the terminal year, not merely aggregate consumption.

In order to achieve consistency, resource balances require that the supply of a sector exceed the total demand upon that sector. In matrix equation form for one region, we have: 31 


$$
X+M+R \geq A X+I+C+E+E_{R}+D,
$$

where $X, M$, and $R$ are vectors of total output, foreign and regional imports, respectively; $A$ is the incremental inputoutput matrix and $\mathrm{AX}$ is, therefore, intermediate demand; $I, C, E, E_{R^{\prime}}$ and $D$ are vectors of incremental investment, 32 consumption, foreign exports, regional exports, and other final demand, respectively. The model permits simultaneous determination of sources of supply for the tradable resources (commodities) in both regions and maximization of the welfare function. 33 This choice is made according to the "comparative cost doctrine" mentioned earlier, which ranks activities with respect to their "total" use of relatively scarce primary factors.

The basic constraints of the model are similar to those found in the simple two-gap model: the supply of domestic savings and supply of foreign exchange. In addition, there are upper limits imposed on production in agriculture. 34 The latter represent sector-specific absorptive capacity, in which the fixed supply of land is assumed to limit expansion in these traditional sectors. In equation form, we have:

$$
S+F \geq \sum_{i=1}^{n} I_{i}+G
$$

$$
\sum_{i=1}^{n} p_{i} E_{i}+F \geq \sum_{i=1}^{n} q_{i} M_{i}
$$

$$
x_{i} \leq \bar{x}_{i}\left[(1+r)^{5}-1\right],
$$


where $\mathrm{S}$ is aggregate national savings (including taxes) and $\mathrm{G}$ is government expenditures; investment here is by sector and includes changes in inventories and replacement (see the Appendix); $F$ is the inflow of foreign assistance; $p$ and $q$ are the foreign exchange prices of exports and imports, respectively; $\bar{x}_{i}$ is the previous peak production in the $i^{\text {th }}$ agricultural sector; and $r$ is the assumed maximum growth rate in that sector.

The model can now be used to compare the results of using various export projections with the results which could have been attained under perfect information. In addition to the Balassa and Maizels projections used in the preceding section, two other projections were evaluated. MacEwan (1971) imposed export limits on the various sectors for 1974-75. These limits are probably on the optimistic side since they represent export levels corresponding to a 7.5 per cent rate of growth. Tims (1968) made a set of projections for the period covered by the Third Five-Year Plan. His estimates paralleled and were in contrast to those of the Plan. He used a sectoral approach in which he estimated sector supply and demand on the basis of detailed information. Our naive projections used in this section were simply extrapolations from the 1960-65 period.

The evaluation procedure was as follows. 35 on the basis of the export projections, the optimal output mix ( $\left.X^{*}\right)$ was calculated by maximizing (WF) subject to (17)-(20) above. 
Since there is a choice among sources of supply, the solution also yielded the optimal import mix $\left(M^{*}\right)$. In equation form, showing the commodity and foreign exchange constraints for both regions together, we have:

$$
X^{*}+M^{*}=A X^{*}+I^{*}+C+E^{P}+D
$$

and

$$
\sum q_{i} M_{i}^{*}=\sum p_{i} E_{i}^{P}+F \quad
$$

where $\mathrm{E}^{\mathrm{P}}$ is the projected exports and $I^{*}$ is the investment allocation necessary to bring about the optimal output mix. This gives maximum aggregate consumption, which is a function of our welfare function.

The economy was then assumed to be "locked" into this output mix due to the resource allocation necessary to bring it about. It was felt that with a five-year period, the rigidity of the economy made resource reallocation difficult so that output capacity could be assumed to be bounded. Thus, the following additional constraints were established: $\quad x_{i} \leq x_{i}^{*} \quad i=1, \ldots, 35$ in each region. Actual 1969 exports were then incorporated into the model, replacing the projected exports, and the system was solved again to obtain the constrained maximum for each projection. The results are given in Table 5. It will be recalled that the welfare function is expressed in terms of increments to per capita consumption over the period. 
Table 5

Evaluations of Export Projections Based Upon a Multisectoral Planning Model for Pakistan

\begin{tabular}{|c|c|c|c|c|c|c|}
\hline & \multirow{2}{*}{$\begin{array}{l}\text { Actual } \\
\text { (Optimal) }\end{array}$} & \multicolumn{5}{|c|}{ Based Upon Projections } \\
\hline & & Balassa & Maizels & Naive & MacEwan & Tims \\
\hline $\begin{array}{l}\text { Increments to per capita } \\
\text { consumption (in rupees } \\
\text { per year) } \\
\text { Shadow Prices }\end{array}$ & 64 & 24 & 26 & 23 & 36 & 40 \\
\hline Foreign exchange & 2.90 & 3.35 & 3.33 & 3.40 & 3.20 & 3.14 \\
\hline $\begin{array}{c}\text { Capital } \\
\text { Parameters } \\
\end{array}$ & 1.80 & 2.01 & 1.98 & 2.03 & 1.92 & 1.90 \\
\hline Growth rate & $4.1 \%$ & 3.18 & $3.15 \%$ & 2.98 & 3.48 & $3.5 \%$ \\
\hline ICOR & 2.28 & 2.15 & 2.20 & 2.19 & 2.30 & 2.32 \\
\hline $\begin{array}{l}\text { Incremental marginal } \\
\text { savings }\end{array}$ & $18.0 \%$ & $15.2 \%$ & 16.28 & 15.88 & 16.68 & $16.8 \%$ \\
\hline
\end{tabular}

Note: The numeraire of the shadow prices is incremental aggregate consump- 
It is evident in line 1 of the table that the values obtained using the export projections were considerably below those that might have been obtained. The discrepancy between the optimal and projected results ranged from 24 (Tims) to 40 (Balassa) rupees per capita per year. This is in comparison to an actual per capita consumption level of 360 rupees per year in 1964-65. Of the five projections noted, it is also evident that the country-specific projections of MacEwan and Tims were substantially in excess of the others.

In terms of the specific commodity export projections, there were perhaps two factors which might have caused such large discrepancies. The global projections of Balassa and Maizels did not foresee the increase in cotton and cotton textile exports. Both had predicted that synthetic substitutes would capture the market. Also, both failed to predict the rise in manufactured exports. This latter rise was foreseen by MacEwan and Tims, with the consequence that their projections fared better relative to the others. The discrepancies in these individual sector projections implied an insufficient expansion in some sectors and overinvestment in others, with a resultant shortfall in incremental per capita consumption.

As in section II, we found it informative to establish another measure for comparing the projections. Looking at equations (21) and (22) above, consider the workings of the 
system. The model provides a solution not only for the prescribed levels of activity, but also for the composition of activity use. Planning on the basis of exporting opportunities, the economy chooses to import or expand domestic production in order to obtain the optimal output mix. Since the interdependence of the model allows us to observe the secondary effects of a misallocation of resources, a further evaluation would be to compare the extent to which the primary resources were misallocated. One indication of this is the change in the shadow prices of foreign exchange and capital when the projections were used. In the general equilibrium context of the model, the shadow price of a resource will reflect the relative scarcity of that resource. Thus, higher prices will be associated with the relatively more effective constraint.

The shadow prices of foreign exchange and capital are listed in lines 2 and 3 of Table 5. There the numeraire of the shadow prices is aggregate rather than per capita, consumption. In each case, the shadow price of foreign exchange exceeds that of capital, indicating a relative scarcity of foreign exchange. The values of both prices for each projection are all greater than the optimal. These higher prices indicate the increased demand for both resources in those sectors where production is limited by the improper allocation of investment. The need for foreign exchange increases as domestic producers would like to substitute foreign imports in those sectors where domestic production may be 
insufficient. Similarly, the shadow price of capital increases because domestic savings are not sufficient to meet the demand for increased investment (production in the capital-producing sectors).

Looking at the shadow prices for each projection, we find that the specific country projections are again superior, with Balassa and the naive worst. This is the result of the more optimistic projections by MacEwan and Tims and their more accurate projections of manufactured goods exports. These exports require more industrial inputs and, therefore, the economy is more sensitive to changes in their level. The projections by MacEwan and Tims also gave a better estimate of the demand for investment, thus causing the constraints to be less effective.

A still further criterion for evaluation is the effect upon the macroeconomic parameters. These are listed in the last 3 lines of Table 5. In terms of growth rates, the projections line up as before. The differences in the incremental capital-output ratios provide some interesting results. Those with an ICOR which was less than the optimal (Balassa, Maizels and the naive) all underestimated export revenues. This caused more concentration of activity in the traditional sectors with lower ICOR's and lower marginal savings rates. In contrast, the MacEwan and Tims projections were overestimates and emphasis was placed upon the industrial sectors with higher ICOR's and marginal savings 
rates. Their two projections also consistently outperformed the other three.

Although it is quite detailed, the model presented in this section remains of course a facsimile of reality. Several important phenomena cannot be incorporated into a linear system of equations. Despite the model's weaknesses, it is nevertheless clear that IDC export projections made on a global basis are of little value in decisions affecting development planning in individual countries. The Balassa and Maizels projections fared considerably more poor than those of MacEwan and Tims, and were in fact only marginally better than the naive extrapolations. As one might expect, the projections based upon more specific and more recent information were superior.

\section{Conclusion}

In recent years, several long-term projections of exports have been undertaken by individual economists and various international agencies. These projections provide the major source of information on the future state of export flows from the developing world. If these projections were accurate, they could fill an important gap in our knowledge of trade flows and their causes and add valuable information to the dynamic process of development. Indeed, one potentially important use of these projections is as an input to decisions. This paper has been an attempt to 
determine the role export projections might play in two particular decision-making contexts.

Two analytic decision models were constructed for this purpose. The models were used to compare the results based upon the export projections with the potential results attainable under perfect information. A set of naive projections was also constructed to serve as a reference point for comparison among the projections. Using an aggregate two-gap model, we found that none of the projections was particularly accurate for use in the disbursement of foreign assistance among LDC's to achieve certain specific growth objectives. On the basis of a multisectoral planning model of the Pakistan economy, it was shown that the mive extrapolations performed as well as the detailed Balassa and Maizels projections. The country-specific forecasts by MacEwan and Tims were far superior to the other projections, although all were relatively inadequate as a potential guide to policy makers in development planning. Our conclusion therefore is that existing long-term export projections are of limited value in these areas of decision making.

As one might expect, the projections based upon the most recent data and designed for country-specific uses were the best. The detailed global projections need to be thoroughly investigated to see if they are subject to any systematic biases and to determine the type and optimal degree of disaggregation used in making projections. 
In the final analysis, projections of all kinds must be evaluated in some particular decision-making context. The models developed in this paper are but a beginning. Much remains to be done to introduce greater realism into them. 


\section{Footnotes}

* I am grateful to Robert M. Stern, Richara C. Porter, Elliot J. Berg, and members of the Research Seminar in International Economics at The University of Michigan for helpful comments on this paper and on an earlier one coauthored with Michael Kennedy. Further credit is due Robert Costrell, who assisted greatly in the computational aspects of the paper. Financial assistance for the research was provided in part by the Center for Research on Economic Development and by the Research Seminar in International Economics at The University of Michgian. The latter was in connection with NSF grant GS-3073.

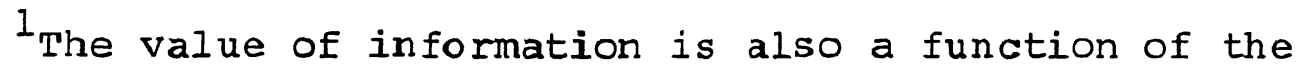
cost involved in its acquisition, which is something we will not consider here.

2 Here, for the aake of exposition, the model is set up using a COR instead of an ICOR. When an ICOR is used, $k$ is subject to policy control as the composition of output is changed.

$3^{3}$ The equality in equation (8) implicitly assumes no excess capacity, and, in addition, that all adjustments in the savings gap will be in the form of frustrated savings. Alternatively, over the planning period, capacity could be expressed as: 


$$
Y_{t} \leq Y_{0}+\frac{1}{k} \sum_{i=0}^{t-1} I_{t}
$$

However, in the comparative static model used for evaluation purposes below, this formulation was not necessary.

${ }^{4}$ If $F$ was not sufficient to fill the larger gap, a more "unpleasant" adjustment process would result. Bottlenecks would develop as intended investment was frustrated or necessary imports were not available, or both, thus resulting in excess capacity and an underutilization of domestic resources.

5 Absorptive capacity may also be sector-specific as will be seen in Section III, where fixed land for agriculture operates as an effective restraint to growth. Sector-specific restraints cannot be treated adequately without the use of a comprehensive sectoral model.

${ }^{6}$ In the remainder of the section, it is assumed that $F$ will be sufficient to fill the larger gap. It is also assumed that the goal of the LDC is to achieve self-sustaining growth, i.e., a given rate of growth with $F / Y$ constant at a low level without the need for concessional funding.

${ }^{7}$ See Vanek (1967), McKinnon (1964), and Chenery and Strout (1966). Also Balassa (1964) and Maizels (1968), whose projections will be evaluated, consider the trade gap as the dominant constraint. 
${ }^{8}$ This is shown by looking at the path of the trade gap when we assume a balanced rate of growth of $\mathrm{Y}$ :

$$
F_{t}^{T}=M_{0}+m\left(Y_{0} e^{r t}-Y_{0}\right)-E_{0} e^{x t} \text {, }
$$

where $\mathrm{Y}$ and $\mathrm{E}$ are written as time paths and $\mathrm{r}$ is the rate of growth. Differentiating with respect to time we see:

$$
\frac{d F^{T}}{d t}=m r Y_{0} e^{r t}-x E_{0} e^{x t},
$$

which implies that in order for $d F^{T} / d t<0$, either $x>r$ or $M_{t} / Y_{t}<M_{t-1} / Y_{t-1}$.

${ }^{9}$ Derived as above we find:

$$
\frac{d F^{S}}{d t}=k \bar{r}^{2} Y_{0} e^{\bar{r} t}-s \bar{r} Y_{0} e^{\bar{r} t},
$$

which implies $\mathrm{dF}^{\mathrm{S}} / \mathrm{dt}<0$ only if $\mathrm{s}>\mathrm{k} \overline{\mathrm{r}}$.

${ }^{10}$ As mentioned, Chenery and strout (1966) found that a low growth rate of exports was often associated with poor "historical" internal performance and a low rate of growth in GNP. The cause probably lay in the reliance for exports upon traditional sectors in which there were relatively low marginal savings rates.

${ }^{1} l_{\text {The multisectoral model will take account of the }}$ secondary effects caused by changes in the parameters or exogenous variables. This will be done by specifying "sectoral internal parameters" and using these to derive the macroaggregates. Thus, the "total" impact of a change in 
export growth can be observed, including its influence on the other parameters.

12 A large part of this section is the result of the work begun by Michael Kennedy which appeared in the paper we co-authored (1970).

${ }^{13}$ Since Balassa's projections were for broad, less developed regions, it was necessary to disaggregate the projections to find the implicit projections for individual countries. The simplest procedure would have been to assume unchanged shares. Instead, the arithmetic average of the 1960 and 1967 shares was used to split up the regional totals. Although this approach is arbitrary, it was felt that some forecast of share changes was necessary in order to disaggregate the regions for this potential important use of projections.

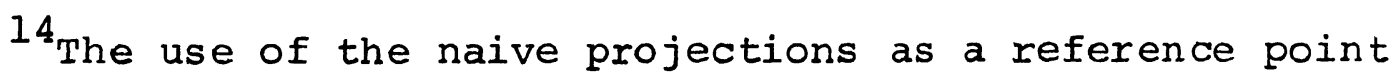
could also establish a measure of the usefulness of the projections as a function of cost.

${ }^{15}$ The 12 countries were selected on the basis of size, geographic location, and stage of development. As will be noted below, the analysis could be extended to cover any number of additional countries. The amount assumed to be allocated was $\$ 4,195$ million, in contrast with $\$ 2,100$ million in assistance received by the countries in 1962. The $\$ 4,195$ million was arrived at by solving the linear system of 
constraints for the amount of assistance needed to allow each LDC to achieve a 20 per cent increase in GNP over the five-year period. This amount is compatible with the implicit estimate found in Chenery and strout (1966), where they demonstrated the need for increasing inflows of aid over time due to widening gaps.

\section{${ }^{16}$ The projections for 1970 were adjusted to a 1967} basis using the growth rate of exports given or implied. The formula used for adjusting Balassa's estimates was, for example:

$$
P_{67}=\exp \left[.7 \ln \left(P_{70} / A_{60}\right)\right]
$$

where $P$ and $A$ refer to projected and actual exports, respectively.

17 The mean squared error is calculated as follows:

$$
M S E=\sum_{i=1}^{n} \frac{\left(\frac{A_{i}-P_{i}}{A_{i}}\right)^{2}}{n} \quad i=1, \ldots, n,
$$

where $A_{i}$ is the actual value in the $i^{\text {th }}$ cell and $P_{i}$ is the predicted value for the cell. The subscripts indicate the number of predictions (cells) involved.

${ }^{18}$ The base year was chosen as 1962 for two reasons. First, the source of data for the model, that is Chenery and strout (1966), used this as its base year. Secondly, a five-year period seemed the most desirable for the constant parameter assumption, and the latest available trade statistics at the time of writing were for 1967. 
${ }^{19}$ The constant, 1/5, was used in equation (11) to assure a smooth growth rate over the period. Ideally, one would want to solve the system for the annual rate of growth, but the form of the model made this impossible.

${ }^{20}$ This can be formulated in terms of a linear programming problem in which, for any initial position and parameter values, the economy could be characterized by a different set of binding constraints. Consider the diagram below in

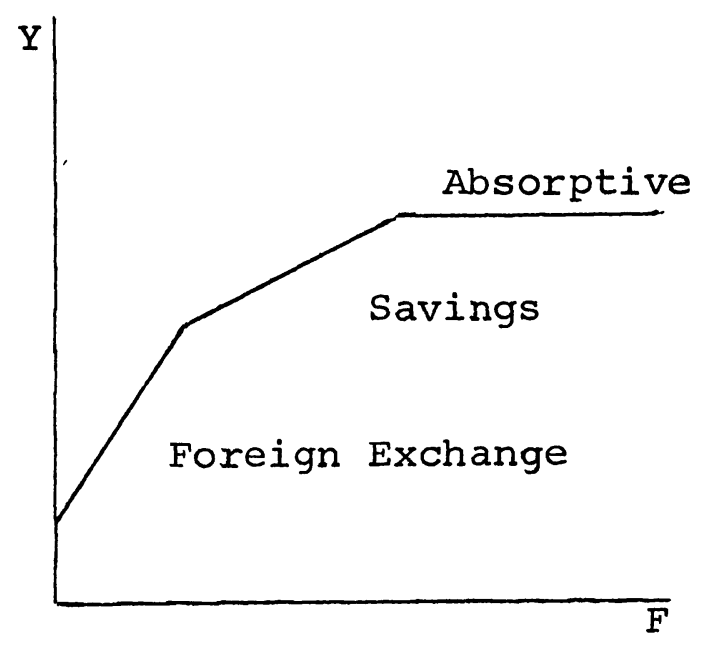
which GNP is plotted as a function of $F$, the amount of foreign aid. At a given point in time, the relationship between aid and income can be shown as a curve made up of three linear segments, corresponding to the foreign exchange, savings, and absorptive constraints. The position of the segments is determined by the initial data, and the slopes are the marginal productivity of aid, which decreases as new constraints become effective.

$21_{\text {This }}$ is the problem of secondary effects referred to earlier.

22 The value of the objective function is found by using:

$$
\sum_{i=1}^{12} \mathrm{Y}_{i} / \sum_{i=1}^{12} \mathrm{YO}_{i}
$$


${ }^{23}$ It should be noted that allocations of aid on the basis of poor projections might cause a change in the effective constraint, thereby changing the productivity of the aid. A change in the productivity means that the rate of growth changes accordingly. If the constraints were as they appeared in footnote 20 above (with the productivity of $F$ falling), then overestimates of export revenues would cause larger variations in growth rates than caused by underestimates.

${ }^{24}$ Since the comparative static model only permits observation of the differences between two equilibrium positions without regard to the adjustment process, this may not be an indication of the total loss involved. In the case of overestimated export revenues, the shortage of foreign exchange might result in a bottleneck causing a severe underutilization of resources, which cannot be incorporated into the model. The loss would only appear as an adverse effect on the rate of growth.

${ }^{25}$ The squared-error loss was calculated as follows:

$$
\text { SEL }=\sum_{i=1}^{12} \frac{\left(g_{i}^{a}-g_{i}^{p}\right)^{2}}{12},
$$

where $g^{a}$ and $g^{p}$ are the growth rates for the optimal and projected, respectively. It was unweighted because each LDC was meant to be treated equally. 
${ }^{26}$ Comparison of these two country results reveals a drawback in using the SEL criterion for evaluation purposes. The examples show that an asymmetry exists in the structure of the model. The absorptive capacity constraint functions as an upper bound on growth while no analogous lower bound exists. An asymmetric loss function would be more desirable, particularly because of the dire consequences of an overestimate of export earnings.

27 This is the simplex criterion of linear programming.

${ }^{28}$ These parameters are calculated as weighted averages of the individual sector parameters.

${ }^{29}$ The latest available trade data in this case were for 1969. All of the variables were adjusted to that year in the evaluation to be presented.

${ }^{30}$ Aggregate consumption was related to individual sector consumption by using linear approximations to Engel functions. Thus, the marginal consumption basket was fixed and no price substitution could take place.

${ }^{31}$ All of the equations and constraints will be shown for a single region unless otherwise specified. Although questions concerning regional disparity are vital, no discussion of the regional aspects of the model is undertaken here. 
${ }^{32}$ In this comparative static model it was necessary to make investment endogenous. This was accomplished using a capital-output matrix and a stock-flow conversion factor. The capital-output matrix is merely a disaggregated form of the simple capital-output ratio.

${ }^{33}$ Unless other constraints become effective, linear programming assures that only one source of supply will be chosen, the "cheapest" one. This is because of the linear form of the transformation curves. In this short planning period, one would not expect to find much import substitution taking place. However, in the evaluations we found that domestic producers looked abroad for scarce inputs, although the foreign exchange constraint did not permit very much importation.

${ }^{34}$ Note that insofar as labor is not taken to be a basic constraint, it is implicitly being assumed that the supply of labor is elastic.

${ }^{35}$ The evaluations were conducted using Pakistan's major exports for which projections had been made. In the cases where no projection was made, the actual value of 1969 exports was used. Details on the projections are available from the author. 


\section{Appendix}

\section{A Multisectoral Model of Pakistan}

The model used in this paper is set out in detail in MacEwan (1971). Here we shall set forth the model in abbreviated form and outline the methodology followed. The variables of the model correspond to total output and imports by sector and consumption, all as increments over the planning period. The constraints are developed below according to their component parts. Unless otherwise indicated, the constraints or equations refer to a single region.

\section{Production and Intermediate Demand}

The technology is a set of production processes with fixed coefficients and constant returns to scale. Each sector's input requirements appear as a column in the inputoutput matrix (A):

$$
\begin{aligned}
& A-(35 \times 35) \text { intermediate input-output matrix } \\
& x-(35 \times 1) \text { vector of gross output. }
\end{aligned}
$$

The intermediate demand becomes the sum of the demands for all sectors, which is the product $\mathrm{AX}$. 


\section{Fixed Capital Requirements}

Investment is made endogenous to the model through the use of a capital output-matrix and a stock-flow conversion factor:

$$
I=H B X-I_{0}
$$

where

$$
\begin{array}{cl}
I-(35 \times 1) & \text { gross investment } \\
B-(35 \times 35) & \text { capital-output matrix } \\
I_{0}-(35 \times 1) & \text { base year investment } \\
\text { H }-(35 \times 35) & \begin{array}{c}
\text { diagonal matrix of specified investment } \\
\text { growth. }
\end{array}
\end{array}
$$

The stock-flow conversion factor changes the fixed capital requirements into a flow for the plan's terminal year according to the formula:

$$
r^{\prime}=\frac{(1+r)^{5}}{\sum_{i=1}^{5}(1+r)^{i}}
$$

where $r^{\prime}$ is the percentage change and $r$ is the rate of growth of investment. The percentage change is taken as .15, which is quite invariant for a five-year period and growth rates around 8 per cent. This formulation assures a smooth growth rate over the period.

Working Capital Requirements

Explicit account is taken of inventories through the specification of a working-capital matrix. This reflects the notion of "work in progress" and also incorporates the 
demand for stocks of materials:

$$
\mathrm{N}=\mathrm{HWX}-\mathrm{w}_{\mathrm{O}}
$$

where

$$
\begin{array}{ll}
N-(35 \times 1) & \text { inventories by sector } \\
W_{0}-(35 \times 1) & \text { base year inventories } \\
W-(35 \times 35) & \text { matrix of working capital requirements. }
\end{array}
$$

\section{Foreign Imports}

Imports are divided between competitive and noncompetitive classes reflecting the economy's inability to substitute domestic production in some industries. This allows the source of supply to be a variable in the problem:

and

$$
M=M^{\prime}+\bar{M}
$$

$$
\overline{\mathrm{M}}=\mathrm{TX}
$$

where

$$
\begin{array}{ll}
M-(35 \times 1) & \text { total imports } \\
M^{\prime}-(35 \times 1) & \text { competitive imports } \\
\bar{M}-(35 \times 1) & \text { noncompetitive imports } \\
T-(35 \times 35) & \text { fixed import requirements. }
\end{array}
$$

\section{Regional Trade}

Regional imports are divided along the lines of foreign imports, with both competitive and noncompetitive components. Since there are only two regions, the regional exports $\left(E_{R}\right)$ are determined from the import equations:

$$
\begin{aligned}
& R=R^{\prime}+\bar{R} \\
& \bar{R}=T^{*} X
\end{aligned}
$$


where

$$
\begin{array}{ll}
R-(35 \times 1) & \text { regional imports } \\
R^{\prime}-(35 \times 1) & \text { competitive regional imports } \\
\bar{R}-(35 \times 1) & \text { noncompetitive regional imports } \\
T^{*}-(35 \times 35) & \text { fixed regional import requirements. }
\end{array}
$$

\section{Exogenous Demand}

Two variables are characterized as exogenous. Increments were fixed over the period as:

$$
\begin{aligned}
& {[\mathrm{REP}]-(35 \times 1) \text { replacement }} \\
& {[\mathrm{GOV}]-(35 \times 1) \text { government expenditures. }}
\end{aligned}
$$

Also exports (E) were taken as exogenous as explained in Section III.

\section{$\underline{\text { Savings }}$}

Aggregate savings are the assumed maximum capabilities of the government through taxation and of individual units. The assumption is based upon a percentage of the value added in each sector, with a distinction made between traditional and industrial sectors:

$$
s=\sum_{i=1}^{6} s_{1} n_{i}+\sum_{i=7}^{35} s_{2} n_{i}
$$

where

$$
\begin{aligned}
& n_{i}=v_{i} x_{i}, \text { and } \\
& v_{i}=1-\sum_{j} a_{j i}
\end{aligned}
$$

where 


$$
\begin{aligned}
& s-\text { (scalar) - aggregate regional savings } \\
& s_{1}-.14 \text { for agricultural sectors } \\
& s_{2}-.24 \text { for industrial sectors } \\
& n_{i}-\text { total value added in sector } \underline{i} . \\
& v_{i}-\text { value added coefficient for sector } \underline{i} .
\end{aligned}
$$

\section{Consumption}

Aggregate consumption is related to sectoral consumption by linear approximations to Engel functions:

$$
c_{i}=k_{i}+d_{i} c
$$

where

$c_{i}$ - consumption in sector $\underline{i}$

$k_{i}$ - intercept term in the $i^{\text {th }}$ Engel function

$d_{i}$ - slope of the $i^{\text {th }}$ Engel function

C - aggregate regional consumption.

Statement of the Model

Maximize $W F=C^{e} / N^{e}+C^{W} / N^{W}$ subject to:

resource balance equation:

$$
\begin{aligned}
X+M+R & \geq A X+\left(H B X-I_{0}\right)+\left(H W X-W_{0}\right)+E_{R}+E+C \\
& +[R E P]+[G O V]
\end{aligned}
$$

foreign exchange constraint:

$$
\sum_{i=1}^{35} p_{i} E_{i}^{e}+\sum_{i=1}^{35} p_{i} E_{i}^{w}+F \geq \sum_{i=1}^{35} q_{i} M_{i}^{e}+\sum_{i=1}^{35} q_{i} M_{i}^{w}
$$

where $F$ is the inflow of foreign assistance and $p_{i}$ and $q_{i}$ are export and import prices respectively. 
capital:

$$
S+F \geq I+N+[R E P]+[G O V]
$$

agricultural capacity:

$$
x_{i} \leq \bar{x}_{i}\left(\left(1+r^{*}\right)-1\right)
$$

where $\bar{x}_{i}$ is the past production peak in the $i^{\text {th }}$ sector and $r^{*}$ is the maximum growth rate of output. 


\section{$\underline{\text { References }}$}

Aho, C. M. and Kennedy, M., 1970, Evaluations of export projections for less developed countries, mimeographed. Balassa, B., 1964, Trade prospects for developing countries (Homewood: Richard D. Irwin).

Bruno, M., 1967, Optimal patterns of trade and development, Review of Economics and Statistics, 49, 545-554.

Bruno, M., 1970, Development policy and dynamic comparative advantage, in NBER, R. Vernon, ed., The technological factor in international trade (New York: Columbia University Press).

Chakravarty, S., 1969, Capital and development planning (Cambridge: MIT Press).

Chenery, H. B., 1961, Comparative advantage and development policy, American Economic Review, 51, 18-51.

Chenery, H. B., and Strout, A. M., 1966, Foreign assistance and economic development, American Economic Review, 56, $679-733$

Dorfman, R., Samuelson, P. A., and Solow, R. M., 1958, Linear programming and economic analysis (New York: MCGraw-Hil1).

Duprez, C. and Kirschen, E. S., 1970, MEGISTOS: A model of world income and trade in 1975 (Amsterdam: North Holland). 
Fei, J. C. H., and Ranis, G., 1968, Foreign assistance and economic development: comment, American Economic Review, 58, 897-911.

GATT, 1962, International trade 1961 (Geneva: GATT).

Khan, A. R., 1967, A multi-sector programming model for regional planning in Pakistan, Pakistan Development Review, 7, 29-65.

Khan, A. R., and MacEwan, A., 1967, Regional current inputoutput tables for the East and West Pakistan economies, Pakistan Institute of Development Economics Research Report Series, no. 63 .

Leamer, E. E., and Stern, R. M., 1970, Quantitative international economics (Boston: Allyn and Bacon). MacEwan, A., 1971, Development alternatives in Pakistan (Cambridge: Harvard University Press). Maizels, A., 1968, Exports and economic growth in developing countries (Cambridge: The University Press).

McKinnon, R., 1964, Foreign exchange constraints in economic development and efficient aid allocation, Economic Journal, 74, 388-409.

OECD, 1965, Techniques of economic forecasting (Paris: OECD). OECD, 1967a, The flow of financial resources to less developed countries 1960-67 (Paris: OECD).

OECD, 1967b, Quantitative models as an aid to development assistance policy (Paris: OECD).

Pakistan, 1970, Reports of the advisory panels for the fourth five-year plan 1970-75, 2 vols. 
Rosenstein-Rodan, P. N., 1957, Notes on the theory of the "Big Push," CENIS, MIT, mimeographed.

Theil, H., 1961, Economic forecasts and policy (Amsterdam: North Holland).

Tims, W., 1968, Analytical techniques for development planning (Karachi: Pakistan Institute of Development Economics ) .

United Nations, 1964, Studies in long-term economic projections for the world economy: aggregate models (New York: UN) .

United Nations, 1960-70, Commodity trade statistics (New York: UN).

United Nations, 1960-70, Yearbook of international trade statistics (New York: UN).

Vanek, J., 1967, Estimating foreign resource needs for economic development (New York: McGraw-Hill). 



\section{CRED Discussion Papers}

No. 1 Elliot J. Berg, “Wage Structure in Less Developed Countries,” January 1968

No. 2 Peter Eckstein, "Accounting Prices as a Tool of Development Planning," February 1968

No. 3 Wolfgang F. Stolper, "Economic Growth and Political Instability in Nigeria: On Growing Together Again," November 1968

No. 4 Euliot J. Berg, "Industrial Relations Systems in Colonial West Africa: A Comparative Analysis of French West Africa and the Gold Coast," December 1968

No. 5 Euriot J. BERG, "Trade Unions and Wage Levels-The Nigerian Case," January 1969

No. 6 Richard C. Porter, "Some Implications of Post-War Primary Product Trends," February 1969

No. 7 Peter Eckstein, "Quantitative Measurement of Development Performance: A Critique by Peter Eckstein and a Reply by Irma Adelman and Cynthia Taft Morris," April 1969

No. 8 Richard C. Porter, "The Effectiveness of Tax Exemption in Colombia," July 1969

No. 9 Peter Eckstein, “Toward an Integrated Theory of Tariffs," August 1969

No. 10 Wolfgang F. Stolper, "Limitations of Comprehensive Planning in the Face of Comprehensive Uncertainty: Crisis of Planning or Crisis of Planners," October 1969

No. 11 Richard C. Porter, "Birth of a Bill Market," August 1970

No. 12 Isaac Ayinde Adalemo, "Distribution of Market Centers, Market Periodicities, and Marketing in Northwestern Nigeria," August 1970

No. 13 ELLIOT J. BERG, "Wages and Employment in Less-Developed Countries," December 1970

No. 14 Thomas L. Hutcheson and Richard C. Porter, "The Cost of Tying Aid: $A$ Method and Some Colombian Estimates," January 1971

No. 15 Rajaona Andriamananjara, "Labor Mobilization: The Moroccan Experience," April 1971

No. 16 C. Michael Aно, "The Use of Export Projections in Allocating Foreign Aid among and Domestic Resources within Developing Countries," July 1971

Discussion Papers in this series contain preliminary results circulated to stimulate comment and criticism. A Discussion Paper should not be reproduced or quoted in any form without permission of the author. 



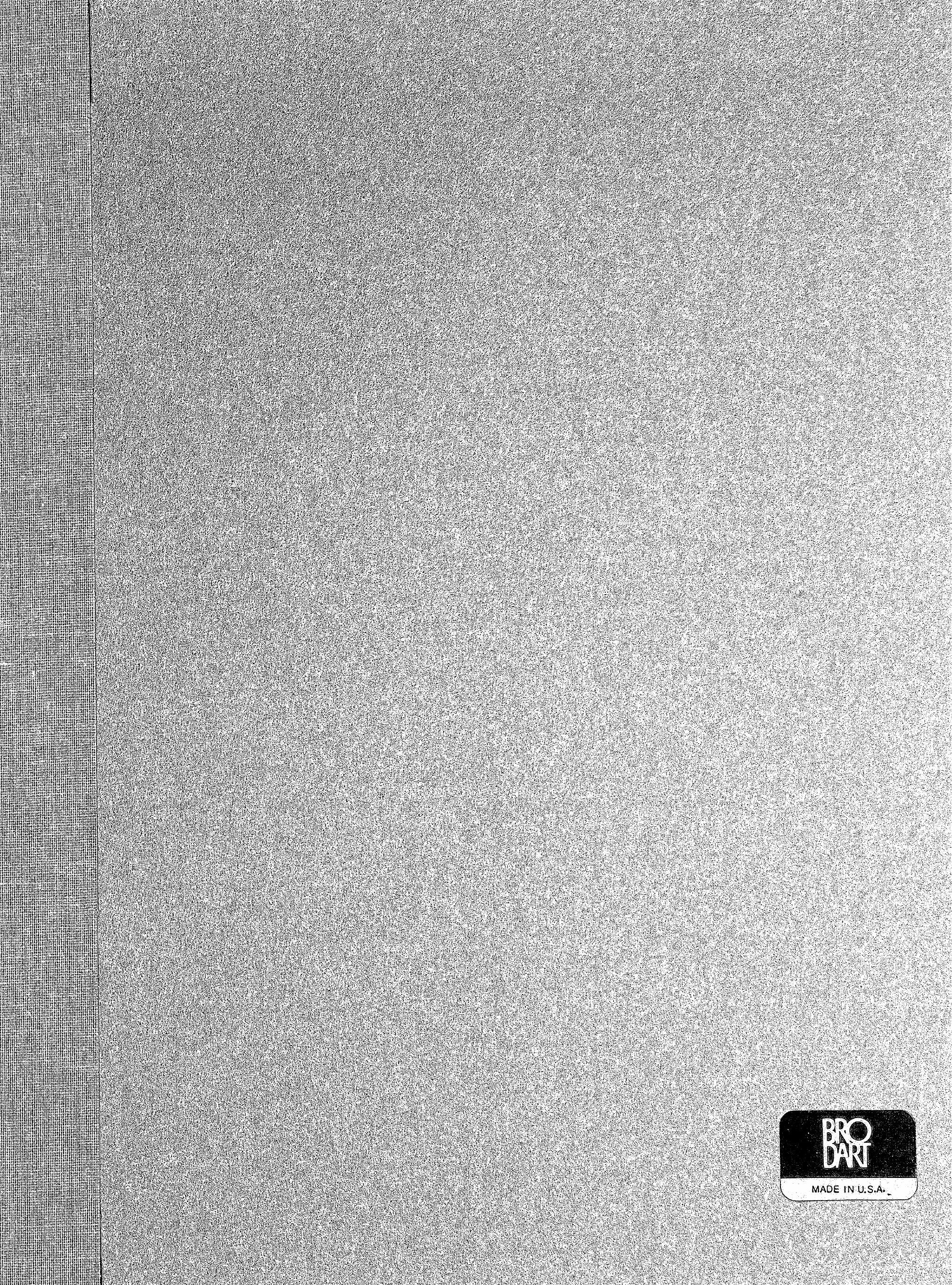




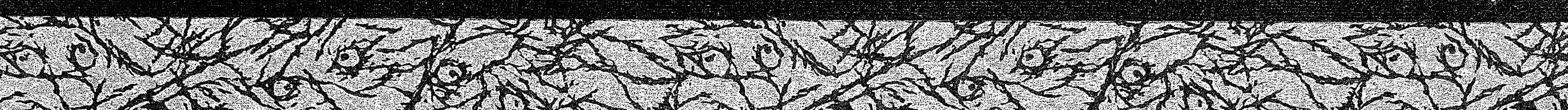

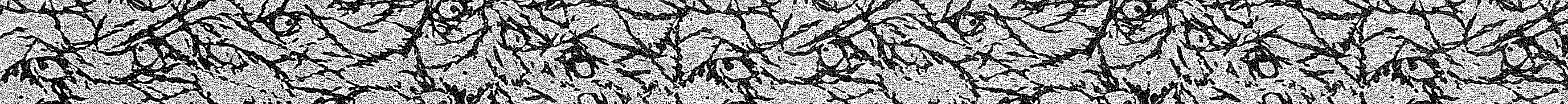

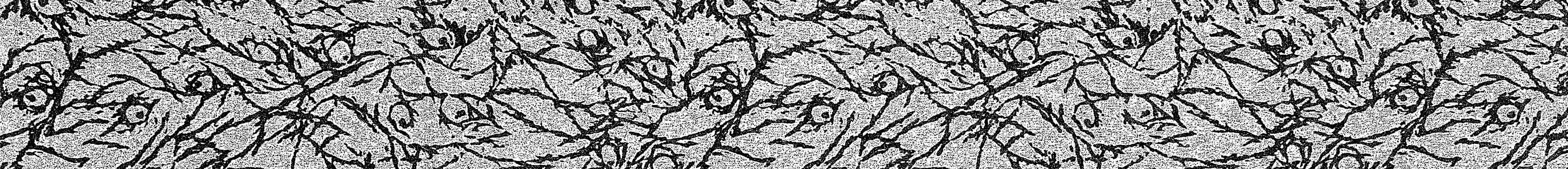

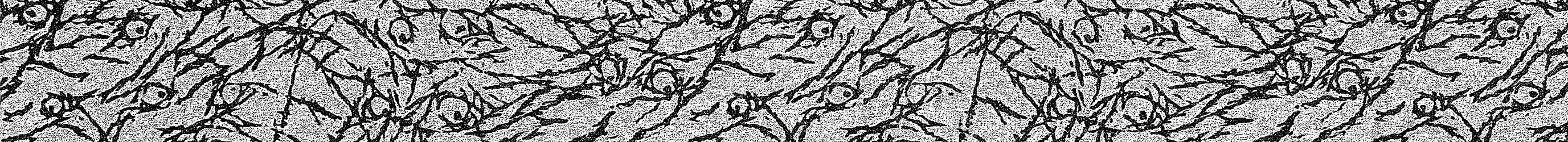

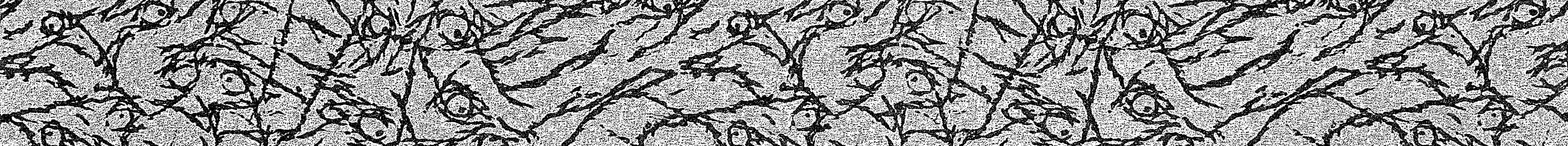

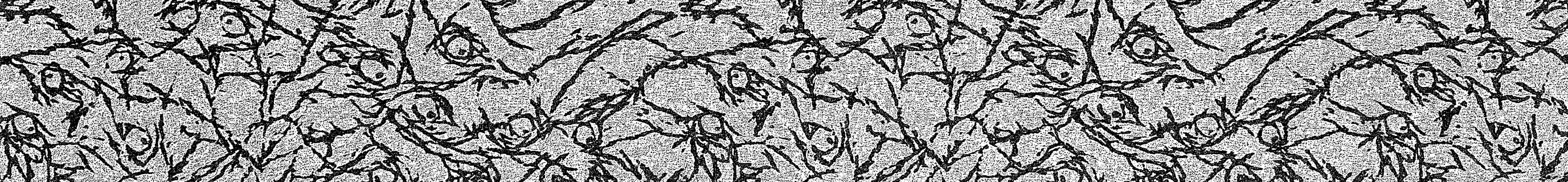

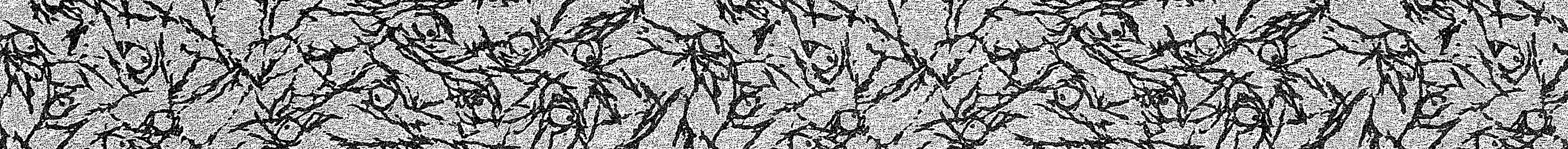

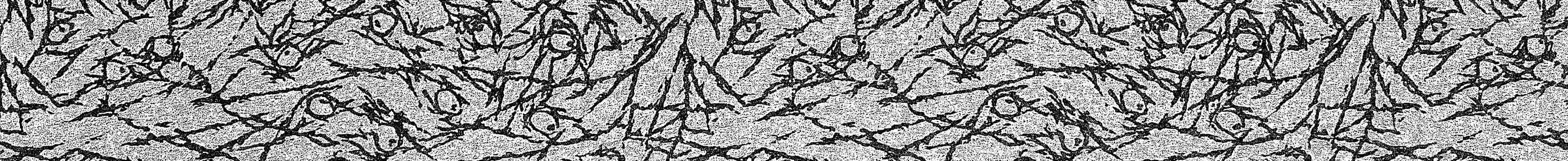
$-7-1+35-5,152$

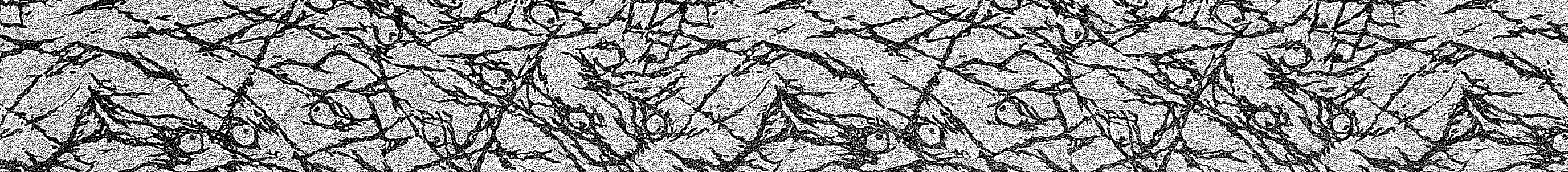

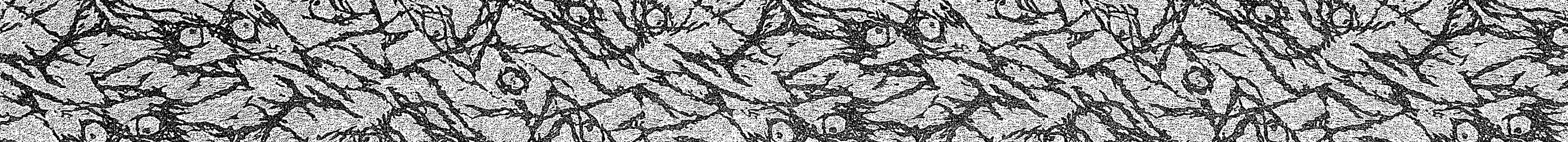

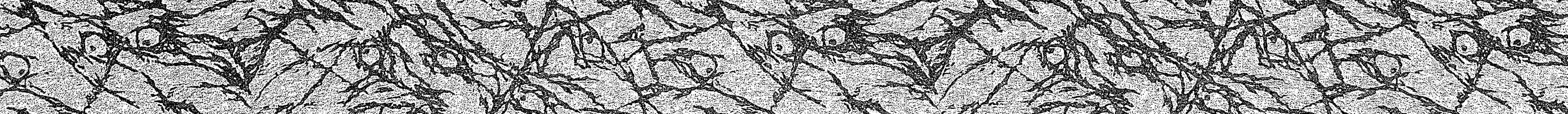

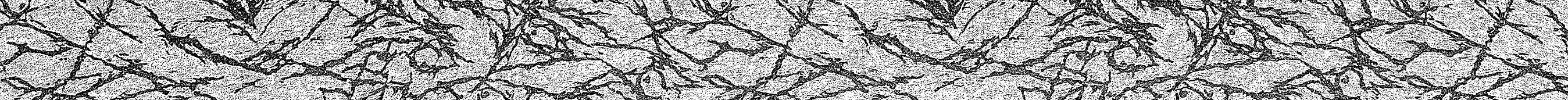

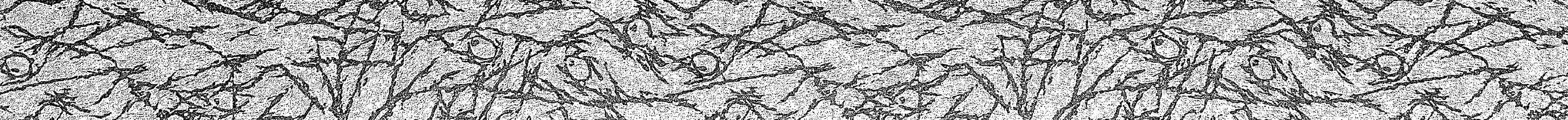

